\title{
The motivation to be sedentary predicts weight change when sedentary behaviors are reduced
}

\author{
Leonard H Epstein", James N Roemmich, Meghan D Cavanaugh, Rocco A Paluch
}

\begin{abstract}
Background: Obesity is correlated with a sedentary lifestyle, and the motivation to be active or sedentary is correlated with obesity. The present study tests the hypothesis that the motivation to be active or sedentary is correlated with weight change when children reduce their sedentary behavior.

Methods: The motivation to be active or sedentary, changes in weight, and accelerometer assessed physical activity were collected for 55 families with overweight/obese children who participated in a nine-week field study to examine behavior and weight change as a function of reducing sedentary behavior. Children were studied in three 3-week phases, baseline, reduce targeted sedentary behaviors by $25 \%$ and reduce targeted sedentary behaviors by $50 \%$. The targeted sedentary behaviors included television, video game playing, video watching, and computer use.

Results: The reinforcing value of sedentary behavior but not physical activity, was correlated with weight change, as losing weight was associated with lower reinforcing value of sedentary behaviors. Reducing sedentary behavior was not associated with a significant change in objectively measured physical activity, suggesting the main way in which reducing sedentary behavior influenced weight change is by complementary changes in energy intake. Estimated energy intake supported the hypothesis that reducing sedentary behaviors influences weight by reducing energy intake.
\end{abstract}

Conclusions: These data show that the motivation to be sedentary limits the effects of reducing sedentary behavior on weight change in obese children.

Trial registration: ClinicalTrials.gov: NCT00962247

\section{Introduction}

The choice to be active or sedentary depends in part on individual differences in the motivation to be active or sedentary, as well as constraints on access to sedentary or active alternatives $[1,2]$. The motivation to be active or sedentary can be operationalized by providing children with the choice to be active or sedentary, varying the behavioral costs to obtain access to the alternatives, and quantifying the amount of work or effort the children will do to gain access to the alternatives. This provides an index of the relative reinforcing value of being active $\left(R R V_{A C T}\right)$ or sedentary $\left(R R V_{\text {SED }}\right)$. The relative reinforcing value of physical activity has been associated with physical activity levels, with children who find

\footnotetext{
* Correspondence: Ihenet@buffalo.edu

Department of Pediatrics, School of Medicine and Biomedical Sciences, University at Buffalo, Farber Hall, Room G56, 3435 Main Street, Building \#26, Buffalo, New York 14214-3000, USA
}

physical activity more reinforcing also being the most active [3-5]. In addition, there are strong individual differences in the reinforcing value of physical activity, as obese children find physical activity less reinforcing than leaner children [6].

Reported time spent watching television, as one component of being sedentary, is cross-sectionally correlated with obesity in children and adults [7-10], as well as being a risk factor for the development of obesity in children [11,12]. Given the role of a sedentary lifestyle in weight gain and the development of obesity, research suggests that reducing sedentary behavior may be a valuable tool in prevention $[13,14]$ and treatment of pediatric obesity $[15,16]$. There are two potential ways in which reducing sedentary behaviors can be associated with weight changes. As sedentary behaviors are reduced, complementary reductions in energy intake may occur,
C Biomed Central

C 2011 Epstein et al; licensee BioMed Central Ltd. This is an Open Access article distributed under the terms of the Creative Commons Attribution License (http://creativecommons.org/licenses/by/2.0), which permits unrestricted use, distribution, and reproduction in any medium, provided the original work is properly cited. 
or as sedentary behaviors are reduced, children may substitute physical activity for sedentary behaviors.

Despite the importance of the motivation to be sedentary or active as a predictor of a child's lifestyle choices, there has been no research on how the motivation to be active or sedentary is associated with weight change when sedentary behaviors are reduced. The purpose of this study is to report on how individual differences in the $R R V_{\text {SED }}$ or $R R V_{\text {ACT }}$ are correlated with weight loss during an intervention when sedentary behaviors are reduced.

\section{Methods}

\section{Participants}

Participants were 56 overweight/obese, 8-12 year old American children, recruited from flyers, a direct mailing, and a pre-existing database. All of the children were considered to be overweight or at risk for overweight, defined as a Body Mass Index (BMI) percentile adjusted for age and sex at or above the $85^{\text {th }}$ percentile [17]. Criteria for participation included the following; at least one parent agreed to help their child reduce targeted sedentary behaviors, and measure usual physical activity and dietary intake; the participating child must have engaged in at least 18 hours of targeted sedentary behaviors per week; could not participate in swimming and/ or weight training for greater than 5 total combined hours per week; no activity restrictions or physical limitations that could interfere with changes in physical activity, such as developmental disability or injury; no psychopathology or developmental disabilities that would limit participation. All procedures and measures were approved by the University at Buffalo Children and Youth Institutional Review Board.

\section{Design and Procedure}

After completing the phone screen families were scheduled for an orientation. During the orientation parents and children completed consent and assent forms, child height and weight were measured, and families were oriented on the TV allowance device, the physical activity monitor, and activity diaries. Interested families were fitted with an accelerometer which was worn on two weekdays and one weekend day.

Families were scheduled for two laboratory sessions. The child's $R R V_{\text {SED }}$ and $R R V_{A C T}$, were measured during the first session, and the accelerometers were calibrated during the second session using a progressive treadmill test. After laboratory testing, families were scheduled for 5 home visits throughout the nine week intervention, and children were scheduled to wear the accelerometer on three randomly selected days, two weekdays and one weekend day. Children were also instructed to selfmonitor time on each sedentary and active behavior to ensure adherence with the experimental manipulation in a seven day diary during the last week of each phase. Activity devices were downloaded at home visits 3-5 and self report diaries were checked for accuracy. Weight was measured at each home visit and height was measured at the last home visit. Reminder phone calls were made to ensure the child wore the activity device on their scheduled day. Parent and child manuals were provided to each family explaining the study goals as well as to provide techniques for praise and reducing sedentary behaviors.

During the first of five home visits, TV Allowance ${ }^{\mathrm{TM}}$ devices were connected to each TV and computer in the home, families were trained on using the devices and asked to maintain their usual pattern of sedentary behaviors, physical activity and dietary intake through the baseline phase; activity devices were fitted to the child, the child was trained on recording in the weekly diary; and weight was measured. During the second home visit each device was checked and TV and computer hours were recorded. At the third home visit, eligibility was determined, amount of screen time was calculated from the allowance devices, and the devices were programmed to decrease TV and computer use by $25 \%$ for the next three weeks. During the fourth home visit, devices were programmed to decrease TV and computer use by $50 \%$ for the next three weeks. Devices were removed at home visit 5 .

Two positive reinforcement techniques were used to facilitate adherence to the experimental protocol, praise and monetary reinforcement. Parents were instructed to praise their children when they observed behavior changes in the appropriate direction, and to be very specific in stating what the praise is for and to be consistent in using praise. Families earned up to $\$ 325.00$ for participation in the 9 week-study. Children earned up to $\$ 15 /$ week during the $25 \%$ and $50 \%$ reduction phases for making the reductions in targeted sedentary behavior (\$90), with the amount proportional to the degree of change, with $\$ 10$ for reaching the decrease goals and an additional $1 \$$ for every hour under their goal up to $\$ 5$. During the baseline phase families could earn up to $\$ 25 /$ week ( $\$ 75$ ) for completing measurements, and up to $\$ 10$ per week ( $\$ 60)$ for completing measurements during the $25 \%$ and $50 \%$ reduction phases. Families also earned $\$ 100$ for completing the study. Families could distribute the family money as they chose.

\section{Measurement \\ Demographic variables and medical history}

Family size, family income, parent educational level and racial/ethnic background were obtained using a standardized questionnaire. Current medical problems, 
including psychiatric diagnoses and eating disorders were assessed at baseline by parent interview.

\section{Weight, height, BMI}

Child weight was assessed by use of a Tanita BWB-800P digital scale. Height was assessed using a Digi-Kit digital stadiometer. On the basis of the height and weight data Body Mass Index (BMI) is calculated according to the following formula: $\left(\mathrm{BMI}=\mathrm{kg} / \mathrm{m}^{2}\right)$. Children were considered overweight if they were at or above the $85^{\text {th }}$ BMI percentile for their age and sex [17].

\section{Liking of activities, food, and videos/computer games}

Liking of the activities, videos or computer games was measured on 7 point Likert-type scales anchored by 1 (Do not like) to 7 (Like very much) [18].

\section{The relative reinforcing value of sedentary behavior}

\section{$\left(R R V_{S E D}\right)$ and physical activity $\left(R R V_{A C T}\right)$}

$R R V_{S E D}$ or $R R V_{A C T}$ is assessed by evaluating how hard a participant will work to obtain access to physical versus sedentary activities [1]. The child first sampled each of the four physical activities and four sedentary behaviors for at least two minutes and then rated them on a scale from 1-7. Children were asked to rank the activities, and the highest rated physical activity and sedentary behavior were chosen for the task. The physical activity alternatives included a balance board, a stationary youth mountain bike, a stepper, and a skipping game, while the sedentary alternative included magazines, puzzles, movies, and Playstation ${ }^{\mathrm{TM}} 2$ video games. The child was instructed how to use the computer-generated task to earn points toward their favorite physical or sedentary activity. The computer displayed three squares where shapes rotated and changed color within each square every time a mouse button was pressed. When all of the shapes matched, the participant earned one point. The child worked on one of two computer monitors, one monitor had the physical activity alternative the other had the sedentary alternative. The reinforcement schedules for both components were initially set at FR4 (fixed ratio 4, which means the participant will earn one point after 4 responses). The schedule increased on a progressive ratio schedule that doubled after 5-points were earned on each schedule. (FR4, FR8, FR16, FR32, FR64, FR128, FR256, FR512, FR 1024 and FR2048). For every five points earned, the participant would receive 2-minutes of time to engage in the activity for which they were playing. The child was able to end the session at any time, they were instructed to tell the experimenter they were all finished when they did not want to earn points any longer. The computer recorded the participants' points earned throughout the session. After instructions were given, the experimenter left the room. $R R V_{\text {SED }}$ and $R R V_{A C T}$ were quantified by the OMAX and the $\mathrm{OMAX}_{\mathrm{ACT}}$, which is the maximal amount of responding at the highest reinforcement schedule completed. An intercom and a video camera were in the room so that the experimenter could hear and see into the experimental room from an adjoining room.

\section{Measurement of television, video and computer game playing at home}

Television, VCR/DVD, video game playing, and computer use was measured using the TV Allowance ${ }^{\mathrm{TM}}$. The device has a memory which recorded the amount of time that the targeted child and each family member used since the unit was installed. The device has been used in ongoing research in our laboratory, and was used as an important component of a previous study that successfully reduced television watching to prevent the development of obesity in youth $[13,19]$. At baseline, unlimited TV and computer hours were set on each device, so that study staff could access the total number of hours for television and computer use for each family member. During the 25 and $50 \%$ decrease reduction phase the TV Allowance ${ }^{\mathrm{TM}}$ was programmed for the sedentary budget for that phase based on baseline amounts. In addition to the TV Allowance ${ }^{\mathrm{TM}}$, selfmonitoring of sedentary behavior was recorded in a daily habit book which assessed reading, homework and use of hand-held computer games and targeted sedentary behaviors that cannot be quantified in this objective way. Recording was part of the intervention methodology to facilitate the child meeting their behavioral goals during the reduction phases.

\section{Physical activity}

The objective measure of physical activity was the Actigraph $^{\mathrm{TM}}$ activity monitor, a small, unobtrusive unidirectional accelerometer with extensive validation in youth as a measure of physical activity [20-23]. The activity monitor was set to record minute by minute measures of physical activity. The activity monitor was worn during school and non-school waking hours on three days (two weekdays and one weekend day) during the last week of each three week period. If a child did not wear their activity monitor on the scheduled day, a day similar to the missed day was rescheduled. Weekly diaries were used in combination with the activity monitor to indicate what physically active and targeted sedentary behaviors the child was engaging in during the last week of each phase of the experiment. The activity monitors were downloaded to a computer at each home visit and weekly diaries were reviewed during the weekly home visit with the family.

To determine levels of physical activity based on energy expenditure (METS or metabolic equivalents) we individually calibrated each accelerometer based on a progressive treadmill test. The $\mathrm{VO}_{2}(\mathrm{~mL} / \mathrm{kg} / \mathrm{min})$ and accelerometer counts/minute were sampled each minute, and the accelerometer values were regressed against $\mathrm{VO}_{2}$ values to estimate energy expenditure for different intensities of physical activity. Based on the regression 
line, rates of accelerometer counts were determined for each participant that corresponded to rest ( 0 counts), 2 METS (7 mL/kg/min), 3 METS (MVPA, $10.5 \mathrm{~mL} / \mathrm{kg} /$ min) and 6 METS (VPA, $21 \mathrm{~mL} / \mathrm{kg} / \mathrm{min})$. Because the accelerometer was only worn for waking hours, and did not include time spent sleeping, we estimated energy expenditure for the remainder of non-accelerometer sampled minutes as expending $1 \mathrm{MET}$ per minute, and computed calories per minute using estimated resting metabolic rate (RMR) using previously published equations for children [24]. Daily RMR calories were converted to RMR calories per minute, then multiplied by number of minutes not sampled by the accelerometer. Energy expenditure estimates while the accelerometer was being worn included RMR component of energy expenditure.

Based on the estimated total daily energy expenditure, we estimated energy intake and changes in energy balance by considering total daily energy expenditure in respect to weight change. If weight was stable over the nine weeks, it was assumed that energy intake = energy expenditure. If children lost weight, it was assumed that one pound of weight loss was equivalent to negative energy balance of $3500 \mathrm{kcals}$, or $55.6 \mathrm{kcal} /$ day. Similarly, a gain of one pound over the nine weeks would be equivalent to positive energy balance of $55.6 \mathrm{kcal} /$ day. Based on the estimated energy expenditure and observed weight change, estimated energy intake and changes in energy balance were calculated.

\section{Analytic Plan}

Repeated measures analysis of variance was used to assess whether changes in targeted sedentary behavior were established to ensure that the targeted behavior had been manipulated by the intervention. Repeated measures analysis of variance was also used to assess changes in body weight, and physical activity. Pearson product moment correlation coefficients were used to assess predictors of weight change, as well as the relationship between changes in targeted sedentary behaviors and physical activity, as well as the relationship between $R R V_{A C T}$ and RRV $V_{S E D}$, $R R V_{\text {ACT }}$ and measured physical activity, and RRV $V_{\text {SED }}$ and total sedentary behavior. Significant factors were then studied in regression models controlling for age, sex and minority status. Significant relationships between weight change and $R R V_{\text {SED }}$ were explored by median splits dividing children into those who decreased or maintained weight $(N=20)$ versus increased $(N=41)$ their weight over the nine weeks of observation.

\section{Results}

The average child was $10.7 \pm 1.2$ years of age, with a height of $57.4 \pm 3.7 \mathrm{in}$, weight of $118.8 \pm 30.5 \mathrm{lbs}$, BMI of $25.0 \pm 4.2$, and zBMI of $1.8 \pm 0.4$. Twenty seven
(48.2\%) of the children were male, and 14 (25\%) were non-Caucasian or minority (Table 1). Changes in weight, targeted sedentary behaviors and physical activity are shown across the three phases in Table 2. The average child had a reduction in targeted sedentary behavior from baseline to $25 \%$ and $50 \%$ reduction phases $(\mathrm{F}(2$, $110)=285.00, \mathrm{p}<0.0001)$, with significant changes from baseline to $25 \%$ ( $\mathrm{p}<0.001$ ), with a further significant reduction from $25 \%$ to $50 \%$ ( $\mathrm{p}<0.001$ ). There was a reduction in targeted sedentary behavior of $67.6 \%$, with the majority of change (53\%) occurring during the initial reduction phase. The changes in sedentary behavior included significant reductions in television watching $(\mathrm{F}(2,110)=197.00, \mathrm{p}<0.001)$ and computer use $(\mathrm{F}$ $(2,110)=40.07, \mathrm{p}<0.001)$. Small, but significant increases in body weight were observed $(\mathrm{F}(2,110)=4.84$, $\mathrm{p}<0.001)$, with significant changes from baseline to $50 \%(\mathrm{p}=0.003)$ phases, but no differences between the $25 \%$ and $50 \%$ phases $(\mathrm{p}=0.20)$. There was little change in physical activity accelerometer counts $(\mathrm{F}(2,110)=$ $0.49, \mathrm{p}=0.61$ ) over phases. In addition, there were no significant changes in average $\operatorname{METS}(F(2,94)=0.60, p$ $=0.55)$, or in the percentage of time below 2 METS ( $F$ $(2,94)=1.61, \mathrm{p}=0.21)$, above $2 \operatorname{METS}(\mathrm{F}(2,94)=1.61$, $\mathrm{p}=0.21)$. Amount of time above 3 METS showed a significant decrease over phases $(\mathrm{F}(2,94)=4.78, \mathrm{p}=0.01)$, with decreases from baseline to the $25 \%(\mathrm{p}=0.03)$ and $50 \%(\mathrm{p}=0.02)$ reduction phases. Estimated energy intake did not significantly change over phases $(F(2,110)$ $=0.49, \mathrm{p}=0.61$ ).

Variables related to weight change included only OMAX $_{\text {SED }}(r=0.31, p=0.022)$. Child age $(p=.71)$, sex $(\mathrm{p}=.64)$, minority status $(\mathrm{p}=.67)$, income $(\mathrm{p}=.38)$, reinforcing value of physical activity $(\mathrm{p}=.72)$ or baseline values of weight $(\mathrm{p}=.45)$, changes in targeted sedentary behavior $(\mathrm{p}=.44)$ or changes in physical activity $(\mathrm{p}=$ .15) were not related to weight change. Multiple regression controlling for child age, sex and minority status did not reduce the impact of $R R V_{\text {SED }}$ on weight change $(\mathrm{p}=0.035)$.

Differences in the motivation to be active or sedentary, and changes in sedentary and active behaviors,

Table 1 Characteristics of the sample $(\mathrm{N}=56)$

\begin{tabular}{ll}
\hline Variable & $\%$ \\
\hline Child sex (M/F) & $48.2(27 / 56)$ \\
$\%$ Minority & $25.0(14 / 56)$ \\
& Mean (SD) \\
Age & $10.7 \pm 1.2$ \\
Height (in) & $57.4 \pm 3.7$ \\
Weight $(\mathrm{lb})$ & $118.8 \pm 30.5$ \\
BMl $\left(\mathrm{kg} / \mathrm{m}^{2}\right)$ & $25.0 \pm 4.2$ \\
zBMl & $1.8 \pm 0.4$ \\
\hline
\end{tabular}


Table 2 Behavior and weight changes during the baseline, 25 and 50\% reduction phases (Mean \pm SEM)

\begin{tabular}{|c|c|c|c|c|}
\hline \multirow[b]{2}{*}{ Variable } & \multicolumn{3}{|c|}{ Sedentary Behavior Reductions Phases } & \multirow[b]{2}{*}{ p } \\
\hline & 0 & $25 \%$ & $50 \%$ & \\
\hline Sedentary behavior (hrs/week) & $34.9 \pm 1.7$ & $16.4 \pm 1.0$ & $11.3 \pm 0.7$ & $0>25>50$ \\
\hline Television watching (hrs/week) & $29.4 \pm 1.7$ & $13.9 \pm 0.9$ & $9.5 \pm 0.6$ & $0>25>50$ \\
\hline Computer games (hrs/week) & $5.5 \pm 0.8$ & $2.5 \pm 0.4$ & $1.8 \pm 0.3$ & $0>25>50$ \\
\hline Weight (lbs.) & $118.8 \pm 4.1$ & $119.2 \pm 4.1$ & $119.6 \pm 4.1$ & $0<50$ \\
\hline Physical activity (counts/min) & $576.9 \pm 23.8$ & $572.4 \pm 25.6$ & $555.7 \pm 24.3$ & NS \\
\hline Average METs & $1.60 \pm 0.05$ & $1.58 \pm 0.04$ & $1.60 \pm 0.05$ & NS \\
\hline$\%$ time below 2 METS & $83.3 \pm 2.4$ & $84.6 \pm 2.4$ & $84.5 \pm 2.4$ & NS \\
\hline$\%$ time above 2 METS & $16.7 \pm 2.4$ & $15.4 \pm 2.4$ & $15.5 \pm 2.4$ & NS \\
\hline$\%$ time above 3 METS & $4.2 \pm 0.7$ & $3.5 \pm 0.6$ & $3.5 \pm 0.6$ & $0>25,50$ \\
\hline Estimated energy intake & $2106.4 \pm 65.7$ & $2173.5 \pm 65.2$ & $2144.3 \pm 74.6$ & NS \\
\hline
\end{tabular}

estimated energy intake and body weight for children who gained $(\mathrm{N}=39)$ or lost $(\mathrm{N}=19)$ weight are shown in Table 3. There was a significant difference in OMAX $_{\text {SED }}$ between children who lost or maintained versus those who gained weight during the study $(\mathrm{F}(1,54$ $=4.79, \mathrm{p}=0.03)$. Figure 1 shows differences in OMAX (left graphs) and the pattern of responding (right graphs), while the top and bottom graphs show motivated responding for sedentary behaviors or physical activity, respectively. As shown in Figure 1, children who maintained or lost weight had lower OMAX and responding over progressive ratio schedules for access to sedentary behaviors than children who gained weight, who worked much harder for sedentary behaviors. There were no differences in $\operatorname{OMAX}_{\mathrm{ACT}}(\mathrm{F}(1,54)$ $=0.11, \mathrm{p}=0.74)$ as a function of whether children lost or maintained versus gained weight during the study. As shown in Table 3, there were no differences in the alterations in any activity variable for children who gained or lost weight over the nine weeks of the study. Children who lost weight reduced energy intake by an estimated $223 \mathrm{kcal} /$ day calories when sedentary behaviors were reduced, while children who gained weight when sedentary behaviors were reduced increased their estimated energy intake by $172 \mathrm{kcal} /$ day $(F(1,54)=$ 13.13, $\mathrm{p}=0.0006$ ).

OMAX $_{\mathrm{ACT}}$ was not significantly related to OMAX $\mathrm{SED}_{\mathrm{S}}$ $(\mathrm{r}=0.07, \mathrm{p}=0.63)$. Similarly, $\mathrm{OMAX}_{\mathrm{ACT}}$ was not correlated with activity counts at baseline $(r=0.12, \mathrm{p}=0.38)$, and OMAX $X_{\text {SED }}$ was not correlated with total sedentary behavior at baseline $(\mathrm{r}=0.07, \mathrm{p}=0.63)$.

\section{Discussion}

The results show that sedentary behavior was successfully manipulated by over $50 \%$, and that children made the majority of the changes during the $25 \%$ reduction phase. These changes were associated with no significant increases in physical activity. We have previously observed minimal changes in physical activity when sedentary behaviors were reduced [25]. Weight change was not associated with changes in physical activity when sedentary behaviors are reduced, suggesting that

Table 3 Differences in behavior for children who lost or gained weight after reduction of sedentary behaviors (Mean \pm SEM)

\begin{tabular}{lccc}
\hline & \multicolumn{2}{c}{ Weight change groups } & \\
\hline Variable & Lost $(\mathbf{N}=\mathbf{1 9})$ & Gained (N = 37) & $\mathbf{p}$ \\
\hline OMAX $_{\text {SED }}$ & $540.4 \pm 143.5$ & $1189.0 \pm 198.4$ & .03 \\
OMAX $_{\text {ACT }}$ & $258.9 \pm 89.4$ & $226.6 \pm 52.3$ & .74 \\
Sedentary behavior (hrs/week) & $-26.3 \pm 2.0$ & $-22.2 \pm 1.6$ & .13 \\
$\quad$ Television watching (hrs/week) & $-22.8 \pm 2.1$ & $-18.4 \pm 1.6$ & .12 \\
$\quad-3.5 \pm 0.8$ & $-3.8 \pm 0.8$ & .83 \\
Computer games (hrs/week) & $-1.2 \pm 0.2$ & $1.8 \pm 0.2$ & .0001 \\
Physical activity (counts/min) & $20.6 \pm 37.4$ & $-42.5 \pm 30.6$ & .22 \\
Average METs & $-0.02 \pm 0.03$ & $-.01 \pm 0.03$ & .78 \\
$\quad 1.45 \pm 1.42$ & $1.10 \pm 1.09$ & .85 \\
$\quad$ \% time below 2 METS & $-1.45 \pm 1.42$ & $-1.10 \pm 1.09$ & .85 \\
\% time above 2 METS & $-0.81 \pm 0.6$ & $-0.78 \pm 0.4$ & .96 \\
Estimated energy intake (kcal) & $-223.2 \pm 105.4$ & .0006 \\
\hline
\end{tabular}




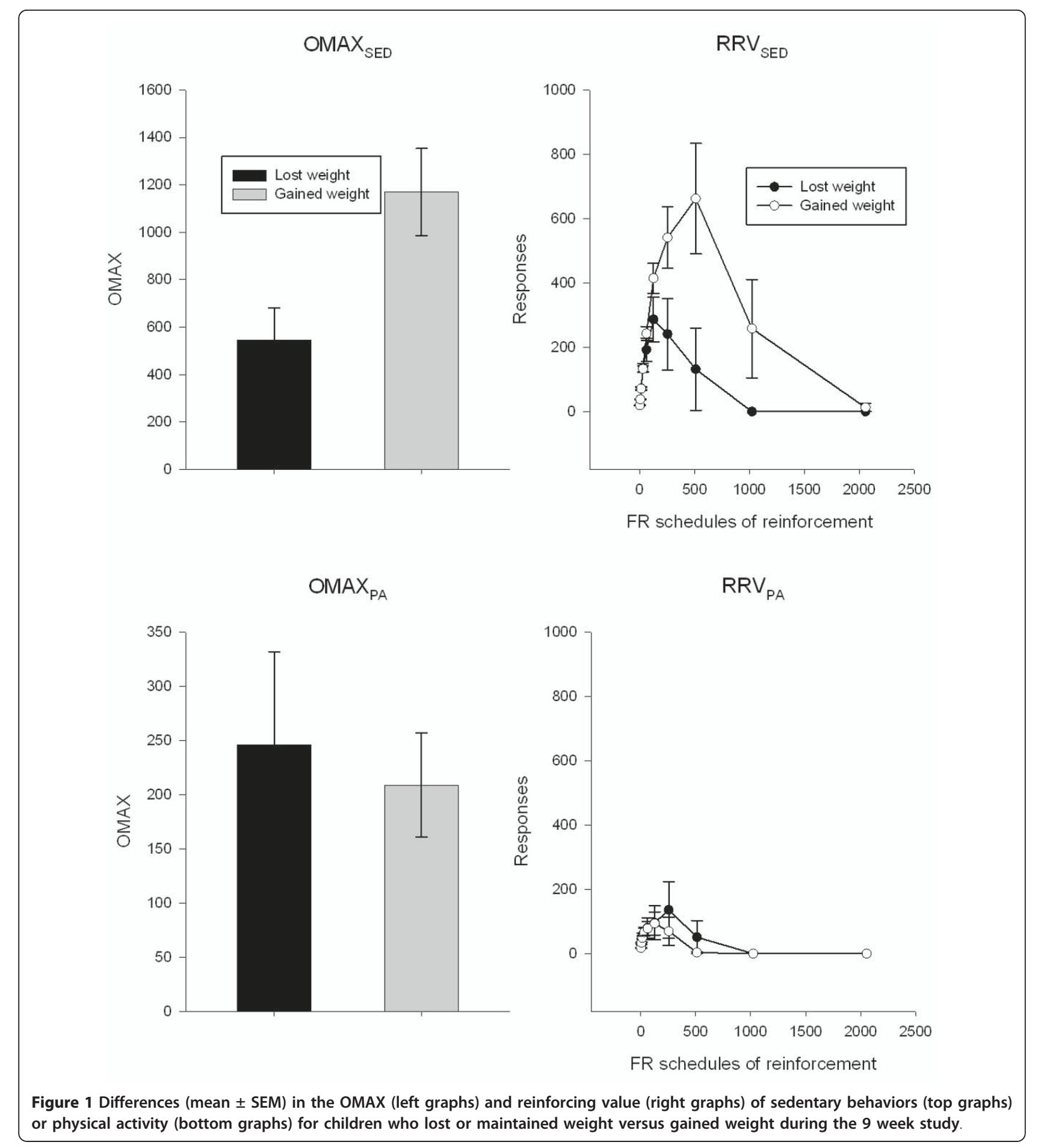

for the average overweight child, reducing sedentary behaviors does not result in greater physical activity and weight loss. This is consistent with cross-sectional research arguing that the effects of sedentary behavior on body weight are not due to changes in activity energy expenditure [26]. In other research we have shown that increasing sedentary behavior results in a reduction in physical activity, suggesting that the relationship between sedentary behavior and physical activity is not symmetric, and the association between these behaviors may only be present in one direction [25].

The variable that was associated with weight change over time was the motivation to be sedentary, which represents the reinforcing value of sedentary behaviors 
such as television watching, watching videos and playing on the computer. These are activities for which obese children allocate a great deal of their time, and time being sedentary may be independent of time being active $[27,28]$, as the motivation to be sedentary is independent of the motivation to be active. If they were direct substitutes for each other, then they would be significantly negatively correlated, and reducing sedentary behaviors would result in an increase in physical activity, which is generally not observed. In the current study the motivation to be active and the motivation to be sedentary were not significantly related.

It is important that only a subset of sedentary behaviors was targeted, to allow the child to choose how to reallocate time that had been allocated for watching television or playing computer games. Since no increases in physical activity were observed, it is likely that children substituted other sedentary behaviors for the targeted sedentary behaviors. Unfortunately, we did not have children record all sedentary behaviors during the reduction phases, so it is not possible to know what sedentary behaviors they engaged in as substitutes.

The question is how is the reinforcing value of sedentary behaviors related to weight change? Weight change is due to change in energy balance, which must be due to either reductions in energy intake or increases in energy expenditure. The absence of increases in physical activity reduces the likelihood that physical activity is a substitute for sedentary behaviors, such that children spontaneously increase their physical activity when sedentary behaviors are reduced. This suggests that changes in energy intake are the component of energy balance that is promoting the weight change. The estimated energy intake data showed that children who lost weight reduced their estimated daily energy intake by $223 \mathrm{kcal} /$ day, while those who gained weight increased their estimated daily energy intake by $172 \mathrm{kcal} /$ day. Other investigators have argued that while sedentary behaviors are correlated with weight, the relationship is not mediated by changes in measured physical activity, but are likely to be mediated by changes in eating and energy intake [26]. We have previously shown in nonoverweight children that energy intake is a reliable complement to shifts in sedentary behavior [19], such that reductions in sedentary behavior paired with eating result in reductions in energy intake. This may be due to the strength of the relationship between eating and engaging in sedentary behaviors when children enter the study. While eating in association with sedentary behaviors is common, and experimental research has shown that increasing television watching increases energy intake [29-31], there is variability in this relationship. If a child never eats in association with television watching, then reducing television watching cannot result in a reduction in energy intake. On the other hand, if a child consumes food often in association with watching television, then reducing television watching may have a large effect on energy intake and body weight.

The motivation to be sedentary is a behavioral phenotype that may lead to a better understanding of factors related to how changing sedentary behavior may relate to changes in energy balance behaviors and weight loss. Given the potential relationship between changes in television watching and energy intake, it is also possible that the motivation to eat is an important factor to predict how reducing sedentary behaviors influences eating. For example, it may be that children who find food more reinforcing would have a harder time reducing food intake when sedentary behaviors are reduced, and they may compensate by increasing intake at other times, or they may resist changes to reduce television watching that is associated with eating, since this would reduce access to powerful reinforcers they want to obtain. This would be an interesting set of studies for future research.

One surprising result was the failure to show that the motivation to be active was related to physical activity, or those high in the motivation to be active were more likely to become more active. We have shown in previous research that the motivation to be active is related to more physical activity $[3,4]$, but these studies included children with a wide variety of motivation to be active as well as a variety of levels of physical activity. In the present study of overweight and obese, sedentary children, the range of motivation to be active and of activity levels was constrained, which can lead to lower relationships if there is little variability in the predictor and/or outcome.

There are limitations to this study in the measurement of activity and diet. While we had objective measurements of physical activity, we did not collect detailed self-reported information on what types of behaviors people engaged in and what types of behaviors people used to substitute for reduced targeted sedentary behaviors. It would have been interesting to know if specific classes of active or sedentary behaviors were changed. For example, recent data suggests that standing rather than sitting may confer health benefits in adults [32], and it would be interesting to know if children stood more or engaged in light physical activity to replace sedentary behaviors and if these changes would be associated with weight loss or improvement in health. Likewise, it would have been interesting to know if other popular sedentary behaviors, such as talking on the phone or texting, replaced television watching or computer game playing. The TV Allowance ${ }^{\mathrm{TM}}$ is a useful behavioral engineering approach to reducing television watching, however, a limitation of using the device is 
that it is possible to overestimate television watching since children may turn on the television and become engaged in an alternative activity and not watch it. This should be minimized since children are reinforced for reducing television watching, but there may be instances in which television watching is overestimated, and the degree of reduction in television watching is underestimated. Physical activity was measured for three days during each phase, and it may have been useful to collect more extended samples of physical activity during each phase [23]. The results point to changes in energy intake, rather than physical activity, as the mechanism for changes in body weight as people reduce their television watching or computer game playing. Estimates of energy intake were consistent with this hypothesis, and accelerometer based activity counts can provide valid information about energy expenditure [20,33]. In addition, self-reports of energy intake are notoriously inaccurate [34], and previous studies using the current methods for reducing sedentary behavior have shown consistent underreporting of energy intake in obese children and adolescents [19]. Despite the challenges in collecting valid dietary intake data, it would be useful to have dietary information that includes dietary intake as well as macronutrient intake.

In summary, the present study replicates previous research that suggests that reducing sedentary behaviors is not associated with an increase in physical activity. The motivation to be sedentary is related to short term weight change when sedentary behaviors are reduced, and this effect may be mediated by changes in energy intake. Thus, one predictor of the effectiveness of programs to reduce sedentary behavior for child weight change may be the motivation to be sedentary.

\section{Acknowledgements}

Appreciation is expressed to Dana D. Winicwicz and Barbara F. Jedrzejck for assisting in the implementation of protocol. This research was funded in part by a grant from the National Institute of Child Health and Human Development, R01 HD39778 awarded to Dr. Epstein.

\section{Authors' contributions}

LHE and JNR designed the study, and LHE obtained the research funding. MDC obtained IRB approval, and supervised study implementation and data collection. LHE and RAP conducted data analysis. LHE wrote the initial draft of the manuscript, and all authors contributed to the interpretation of data and the writing of the manuscript. All authors read and approved the final manuscript.

\section{Competing interests}

Dr. Epstein is a consultant to Kraft foods and NuVal. The other authors do not have any potential conflict of interests.

Received: 24 June 2010 Accepted: 22 February 2011

Published: 22 February 2011

\section{References}

1. Epstein LH, Saelens BE: Behavioral economics of obesity: Food intake and energy expenditure. In Reframing health behavior change with behavioral economics. Edited by: Bickel WK, Vuchinich RE. Mahwah, N.J: Lawrence Erlbaum; 2000:293-311.

2. Epstein $L H$, Roemmich $J \mathrm{~N}$ : Reducing sedentary behavior: Role in modifying physical activity. Exercise and Sport Science Reviews 2001, 29:103-108.

3. Epstein LH, Kilanowski CK, Consalvi AR, Paluch RA: Reinforcing value of physical activity as a determinant of child activity level. Health Psychology 1999, 18:599-603.

4. Roemmich JN, Barkley JE, Epstein LH, et al: Association of liking and reinforcing value with children's physical activity. Physiology and Behavior 2008, 93:1011-1018.

5. Barkley JE, Epstein LH, Roemmich JN: Reinforcing value of interval and continuous physical activity in children. Physiology and Behavior 2009, 98:31-36.

6. Epstein $L H$, Smith JA, Vara $L S$, Rodefer JS: Behavioral economic analysis of activity choice in obese children. Health Psychology 1991, 10:311-316.

7. Andersen RE, Crespo CJ, Bartlett SJ, Cheskin LJ, Pratt M: Relationship of physical activity and television watching with body weight and level of fatness among children: Results from the Third National Health and Nutrition Examination Survey. Journal of the American Medical Association 1998, 279:938-942.

8. Crespo CJ, Smit E, Troiano RP, et al: Television watching, energy intake, and obesity in US children: results from the third National Health and Nutrition Examination Survey, 1988-1994. Archives of Pediatrics and Adolescent Medicine 2001, 155:360-365.

9. Tucker LA, Bagwell M: Television viewing and obesity in adult females. American Journal of Public Health 1991, 81:908-911.

10. Tucker LA, Friedman GM: Television viewing and obesity in adult males. American Journal of Public Health 1989, 79:516-518.

11. Dietz WH, Gortmaker SL: Do we fatten our children at the television set? Obesity and television viewing in children and adolescents. Pediatrics 1985, 75:807-812.

12. Gortmaker SL, Must A, Sobol AM, et al: Television watching as a cause of increasing obesity among children in the United States, 1986-1990. Archives of Pediatrics and Adolescent Medicine 1996, 150:356-362.

13. Epstein $\mathrm{LH}$, Roemmich $\mathrm{JN}$, Robinson $\mathrm{JL}$, et al: A randomized trial on the effects of reducing television on BMI in young children. Archives of Pediatrics and Adolescent Medicine 2008, 162:239-245.

14. Robinson TN: Reducing children's television viewing to prevent obesity: a randomized controlled trial. Journal of the American Medical Association 1999, 282:1561-1567.

15. Epstein $L H$, Valoski $A M$, Vara $L S$, et al: Effects of decreasing sedentary behavior and increasing activity on weight change in obese children Health Psychology 1995, 14:109-115.

16. Epstein LH, Paluch RA, Gordy CC, Dorn J: Decreasing sedentary behaviors in treating pediatric obesity. Archives of Pediatrics and Adolescent Medicine 2000, 154:220-226.

17. Kuczmarski RJ, Ogden CL, Guo SS, et al: CDC growth charts for the United States: Methods and development. Vital Health Statistics. Series 11, Volume 246 Hyattsville, MD: National Center for Health Statistics; 2002, 1-90.

18. van Laerhoven $\mathrm{H}$, van der Zaag-Loonen HJ, Derkx BH: A comparison of Likert scale and visual analogue scales as response options in children's questionnaires. Acta Paediatrica 2004, 93:830-835.

19. Epstein $L H$, Roemmich JN, Paluch RA, Raynor HA: Influence of changes in sedentary behavior on energy and macronutrient intake in youth. American Journal of Clinical Nutrition 2005, 81:361-366.

20. Ekelund U, Sjostrom M, Yngve A, et al: Physical activity assessed by activity monitor and doubly labeled water in children. Medicine and Science in Sports and Exercise 2001, 33:275-281.

21. Freedson PS, Sirard J, Debhold E, et al: Calibration of the Computer Science and Applications, Inc. (CSA) accelerometer. Medicine and Science in Sports and Exercise 1997, 29:S45.

22. Trost SG, Ward DS, Moorehead SM, et al: Validity of the computer science and applications (CSA) activity monitor in children. Medicine and Science in Sports and Exercise 1998, 30:629-633.

23. Trost SG, Pate RR, Freedson PS, Sallis JF, Taylor WC: Using objective physical activity measures with youth: how many days of monitoring are needed? Medicine and Science in Sports and Exercise 2000, 32:426-431.

24. Firouzbakhsh S, Mathis RK, Dorchester WL, et al: Measured resting energy expenditure in children. Journal of Pediatric Gastroenterology and Nutrition 1993, 16:136-142. 
25. Epstein LH, Roemmich JN, Paluch RA, Raynor HA: Physical activity as a substitute for sedentary behavior in youth. Annals of Behavioral Medicine 2005, 29:200-209.

26. Jackson DM, Djafarian K, Stewart J, Speakman JR: Increased television viewing is associated with elevated body fatness but not with lower total energy expenditure in children. American Journal of Clinical Nutrition 2009, 89:1031-1036.

27. Biddle SJ, Gorely T, Marshall SJ, Murdey I, Cameron N: Physical activity and sedentary behaviours in youth: issues and controversies. Journal of the Royal Society for the Promotion of Health 2004, 124:29-33.

28. Marshall SJ, Biddle SJ, Gorely T, Cameron N, Murdey I: Relationships between media use, body fatness and physical activity in children and youth: a meta-analysis. International Journal of Obesity and Related Metabolic Disorders 2004, 28:1238-1246.

29. Temple JL, Giacomelli AM, Kent KM, Roemmich JN, Epstein LH: Television watching increases motivated responding for food and energy intake in children. American Journal of Clinical Nutrition 2007, 85:355-361.

30. Bellissimo N, Pencharz PB, Thomas SG, Anderson GH: Effect of television viewing at mealtime on food intake after a glucose preload in boys. Pediatric Research 2007, 61:745-749.

31. Matheson DM, Killen JD, Wang Y, Varady A, Robinson TN: Children's food consumption during television viewing. American Journal of Clinical Nutrition 2004, 79:1088-1094.

32. Owen N, Healy GN, Matthews CE, Dunstan DW: Too much sitting: the population health science of sedentary behavior. Exercise and Sport Sciences Reviews 2010, 38:105-113.

33. Plasqui G, Westerterp KR: Physical activity assessment with accelerometers: an evaluation against doubly labeled water. Obesity (Silver Spring) 2007, 15:2371-2379.

34. Bandini LG, Schoeller DA, Cyr HN, Dietz WH: Validity of reported energy intake in obese and non-obese adolescents. American Journal of Clinical Nutrition 1990, 52:421-425.

doi:10.1186/1479-5868-8-13

Cite this article as: Epstein et al: The motivation to be sedentary predicts weight change when sedentary behaviors are reduced. International Journal of Behavioral Nutrition and Physical Activity 2011 8:13.

\section{Submit your next manuscript to BioMed Central and take full advantage of:}

- Convenient online submission

- Thorough peer review

- No space constraints or color figure charges

- Immediate publication on acceptance

- Inclusion in PubMed, CAS, Scopus and Google Scholar

- Research which is freely available for redistribution

Submit your manuscript at www.biomedcentral.com/submit 